\title{
Efficacy and safety of vaginal misoprostol in second trimester medical termination of pregnancy
}

\author{
Dr.V B Bangal ${ }^{1}$,Dr.Nisarg H Patel ${ }^{2}$,Dr.Sai.K. Borawake ${ }^{3}$ \\ 1. Professor, 2. Postgraduate student, 3. Postgraduate student \\ Dept.Obstetrics and Gynecology, Rural Medical College, Loni, Ahmednagar, Maharashtra State.413736
}

\begin{abstract}
Search for safe and effective method for second trimester termination of pregnancy continue from the time, when pregnancy termination was legalized through MTP act in India. With the knowledge about the potent uterotonic potential of misoprostol , a synthetic prostaglandin analog, it is being (off label) used for second trimester termination of pregnancy with satisfactory results. Various dosage schedules and routes have been tried for this purpose .Present study was carried out to know the efficacy and safety of vaginal administration of misoprostol for second trimester of pregnancy .One hundred forty eight women seeking termination of pregnancy in second trimester, for various indications as per MTP act, over three years period at government approved MTP center, attached to Medical college hospital, were included in the study .Initial dose of 400 microgram of misoprostol by per vaginal route ,followed by 200 microgram was used for induction of abortion. Overall success rate was 92 percent and average induction abortion interval was 14 hours. There were no serious side effects or complications related to misoprostol .Average dose required for complete abortion was 1200 micrograms .Misoprostol was found to be safe and effective for second trimester medical termination of pregnancy.
\end{abstract}

$\underline{\text { Keywords - Vaginal misoprostol, Medical termination of pregnancy, Second trimester termination of pregnancy }}$

\section{INTRODUCTION:}

Search for safe and effective method for termination of pregnancy in second trimester continues, since pregnancy termination was legalized through medical termination of pregnancy( MTP) act in India .With increasing use of obstetric ultrasonography for assessment of fetal well being in second trimester, many fetal structural abnormalities are being diagnosed. In addition to the gross fetal structural abnormalities, other indications for second trimester termination of pregnancy are related to either unprotected intercourse or failure of contraceptive measures. Over last few decades, many methods of second trimester termination have been tried with reasonable success[1].Among these, ethacridine lactate solution has proved to be safe and effective as an abortificient The drawbacks of this method being, relatively longer induction abortion interval and higher rates of incomplete abortion, requiring surgical evacuation.

Misoprostol, synthetic prostaglandin analogue, originally approved by FDA for treatment of gastric ulcer has been found to have good uterotonic potential. Till date, it is not a approved drug by FDA for pregnancy termination in second trimester. Misoprostol is being (off label) used for termination of pregnancy in different doses and by different routes, in between 13 and 20 weeks with satisfactory results[2-5]. Misoprostol is cheap, stable at room temperature, easily available and has good uterotonic potential without any serious drug related side effects. Induction abortion interval and the rate of complete abortion are higher than previously used methods. Present study was carried out to evaluate the efficacy and safety of vaginal misoprostol in lower dose for medical termination of pregnancy in second trimester.

\section{MATERIAL AND METHODS:}

A retrospective analysis of cases of second trimester medical termination of pregnancies was carried out at Pravara Rural Hospital, a tertiary care teaching institute in Ahmednagar district of Maharashtra. Pravara Rural Hospital has a Government approved centre for MTP since last 25 years. Pregnant women seeking MTP in second trimester of pregnancy were counseled regarding various options and their safety. Advice regarding subsequent contraception and sterilization operation was given to them. One hundred and forty eight women opted second trimester termination during three years period (Jan 2009 - Dec 2011).

All cases were admitted in the ward. A detailed information regarding age, marital status ,education ,socio economic conditions, duration of amenorrhoea, gravidity, parity, previous spontaneous or induced abortions and medical diseases was recorded. General, systemic and bimanual examination was performed to assess duration of pregnancy and to rule out cervico-vaginal infections. Ultrasonography was performed, when there was discrepancy in assessment of gestational age. Blood investigations like hemoglobin, blood grouping and Rh typing, bleeding and clotting time were done. Routine urine examination was done to rule out urine infections. All women were advised to undergo serological test for syphilis, 
serum hepatitis and HIV. Women with organic heart disease, renal disorders, thrombophilia, moderate to severe anemia, asthma, uterine anomalies and having scar of previous uterine surgery, were excluded from study.

Initial dose of $400 \mu \mathrm{g}$ of misoprostol was administered in posterior fornix of vagina and a dose of $200 \mathrm{ug}$ was repeated every four hourly till complete abortion. Maximum of six doses were administered. The case was declared as failure of misoprostol if abortion did not take place in 24 hours. Such cases were managed by other methods of MTP. Cases were monitored for progress of abortion, by observing uterine contractions, per vaginal bleeding, cervical dilatation and expulsion of products of conception. Vital parameters were monitored for the evidence of side effects of misoprostol. Side effects of the drug were managed by symptomatic treatment. If there was active bleeding before expulsion of products of conception, oxytocin (10 U) drip was started to augment the process of abortion .Criteria for success of misoprostol was defined as completeness of abortion process within 24 hours of initial instillation of vaginal misoprostol. Abortion process was taken as complete, when fetus and placenta with membranes were expelled completely without any surgical intervention.

\section{RESULTS:}

Majority of the women seeking abortion were in the age group of 20 and 30 years. They were from poor socio economic back ground with average of eight years of school education. They were multiparous women with average of 2 or 3 children in the family .The average duration of pregnancy at the time of MTP was 16 weeks (Table 1).

Unplanned nature of the pregnancy was the commonest reason (52\%) for termination of pregnancy .Gross structural abnormalities of fetus like anencephaly, Dandy walker syndrome ,spinal cord anamolies ,renal agenesis or dysplastic or polysystic kidneys ,cardiac abnormalities, gastrointestinal and abdominal wall related malformations ( $35 \%$ ) were the second most common reasons for MTP .Failure of contraceptive method or previous sterilization operation was the reason for seeking MTP in remaining cases (Table 2).

The average induction abortion interval was 14 hours in the present study .It ranged from 6 hours to 24 hours (Table 3). The induction abortion interval was less in pregnancies above 16 weeks as compared to pregnancies below 16 weeks .The overall success rate of misoprostol as abortificient was 92 percent .Remaining cases aborted after 24 hours .The average dose required foe complete abortion was 1400 micrograms . Only two cases required check curettage for incomplete abortion. The common drug related side effects were cramp like pain in lower abdomen, nausea, vomiting, diarrhoea ,rigors and fever (Table 4).There was no major side effect requiring additional hospitalization .All cases responded to symptomatic treatment .The side effects were dependant on the dose of misoprostol.

Table 1: The characteristics of the abortion seekers

\begin{tabular}{|l|l|l|}
\hline Sr. No. & Characteristics & Value \\
\hline 1 & Age (years) $($ Mean \pm SD) & $23.30 \pm 3.52$ \\
\hline 2 & Parity (Mean \pm SD) & $2.8 \pm 1.22$ \\
\hline 3 & Gestational age (weeks) (Mean \pm SD) & $16.6 \pm 2.02$ \\
\hline 4 & Married status & $96 \%$ \\
\hline
\end{tabular}

Table 2: Indications for medical termination of pregnancy

\begin{tabular}{|l|l|l|l|}
\hline Sr. no. & Indications & No. of cases & Percentage \\
\hline 1 & Unplanned pregnancy & 78 & 52.70 \\
\hline 2 & Fetal anomalies & 52 & 35.13 \\
\hline 3 & $\begin{array}{l}\text { Failure of } \\
\text { contraceptives }\end{array}$ & 18 & 12.16 \\
\hline \multicolumn{1}{|c|}{ Total } & 148 & 100 \\
\hline
\end{tabular}


Table 3: Induction-Abortion interval

\begin{tabular}{|l|l|l|l|}
\hline Sr. no. & $\begin{array}{l}\text { Induction-Abortion } \\
\text { interval }\end{array}$ & $\begin{array}{l}\text { No. of cases } \\
(\mathbf{n = 1 4 8})\end{array}$ & Percentage \\
\hline 1 & $<12$ hours & 15 & 10.01 \\
\hline 2 & $12-18$ hours & 98 & 66.21 \\
\hline 3 & $19-24$ hours & 23 & 15.54 \\
\hline 4 & $>24$ hours & 12 & 8.10 \\
\hline & Total & 148 & 100 \\
\hline
\end{tabular}

Table 4: side effects and complications related to misoprostol

\begin{tabular}{|l|l|l|l|}
\hline Sr. no. & $\begin{array}{l}\text { Side effects \& } \\
\text { complications }\end{array}$ & $\begin{array}{l}\text { No. of cases } \\
(\mathbf{n = 1 4 8})\end{array}$ & Percentage \\
\hline 1 & Pain in abdomen & 32 & 21.62 \\
\hline 2 & Nausea/vomiting & 16 & 10.81 \\
\hline 3 & Fever / chills & 08 & 05.40 \\
\hline 4 & Incomplete abortion & 02 & 01.35 \\
\hline 5 & Diarrhoea & 06 & 04.05 \\
\hline
\end{tabular}

\section{DISCUSSION:}

Safe and legal abortion is considered to be a key intervention for improving women's health and quality of life.[6] The contraceptive practices in rural area, among less educated couples are still unsatisfactory. This results in unwanted pregnancies requiring termination. A significant number of women use medical termination of pregnancy (MTP) to control the family size and birth spacing [7]. As a result, an overwhelming proportion of induced abortions (6.7 million annually-an indirect estimate) take place all over the country .Termination of pregnancy is carried out by many trained and untrained doctors .MTP related complications are common in the hands of untrained doctors. Although several methods have been tried over the years with varying success, the ideal method for mid-trimester abortion remains elusive, as indicated by the constant search for new methods $[8,9,10,11,12]$.Medical methods for induced abortion have emerged over the past two decades as safe, effective, and feasible alternatives to surgery. Nonsurgical alternatives expand a woman's treatment options and, in turn, the quality of care [13]. Moreover, in some settings, surgical options are not available to women or are not medically feasible. Ethacridine lactate is being used for more than three decades in India with satisfactory results. [10] However, its use has certain disadvantages such as a longer instillation abortion interval, a higher failure rate and more chances of incomplete abortion.[11,12] Misoprostol is a synthetic E1 prostaglandin (PGE1) developed and approved originally for the prevention of gastric ulcers. Misoprostol is not approved by the United States Food and Drug Administration for uterine evacuation in second trimester of pregnancy .Many workers have used this drug and have reported its safety and efficacy with various dose regimens ,combinations and routes of administration. The dose of misoprostol used in the present study was lowest in comparison with other workers and has shown equally good result .As the side effects of the drug are dose dependant, it is suggested that lowest effective dose be used for termination of second trimester of pregnancy.

\section{CONCLUSION:}

Vaginal administration of Misoprostol is effective and safe method for medical termination of pregnancy in the second trimester .It has shorter induction abortion interval and produce minor side effects .It requires short hospital stay and less supervision during hospitalization. 


\section{REFERENCES:}

1. Nagaria T,Sirmor N.Intravaginal misoprostol for termination of second trimester pregnancy.J Obstet Gynecol India.2007;57:435-438

2. Wong KS,Ngai CS,Yeo EL et al.A comparison of two regimens of intravaginal misoprostol for termination of second trimester of pregnancy:a randomized comparative trial .Hum Reprod 2000;15:709-12

3. Herabutya Y,Chanrachakul B,Punyavachira P,Vaginal misoprostol in termination of second trimester of pregnancy.J Obstet Gynecol Res 2000;26:121-5

4. Pongsatha S,Tongsong T, Second trimester pregnancy termination with $800 \mathrm{mcg}$ vaginal misoprostol .J Med Assoc Thai 2001;84:859-63

5. Herabutya Y,Chanrachakul B,Punyavachira P . Second trimester pregnancy termination:A comparison of 600 and 800 micrograms of intravaginal misoprostol. J Obstet Gynecol Res 2001;27:125-8

6. Dhillon BS, Chandhiok N, Kambo I, Saxena NC. Induced abortion and concurrent adoption of contraception in the rural areas of India (an ICMR task force study). Indian J Med Sci 2004; 58:478-84

7. Tejal P, Bakul A. 17 year review of voluntary termination of pregnandy (MTP). J Obstet Gynecol India 2006;56:522-8

8. Goyel BK, Singh G. Mid trimester MTP using endocervical PGE2 gel and serial intramuscular carboprost. MJAFI 2000;56:37-9

9. Goldberg AB, Greenberg MB, Darney PD. Misoprostol and pregnancy. N Engl J Med 2001;344:38-47

10. FOGSI ICOG Consensus Guidelines. Medical termination of pregnancy. Newsletter of the Indian College of Obstetricians and Gynecologists. Mumbai: FOGSI, 2005:36

11. Chaudhuri S, Mitra SN, Chaudhuri N, Chattopadhya D, Bannearjee D, Bose S. A comparison of intravaginal misoprostol with extra amniotic ethacridine lactate for second trimester MTP. Obstet Gynecol India 2006;56:518-21

12. Lalitkumar S, Bygdeman M, Genmzell-Danielsson K. Mid trimester induced abortion: a review. Hum Reprod Update 2007;13:37-52

13. Borgatta L, Mullally B, Vragovic O, et al. Misoprostol as the primary agent for medical abortion in a low-income urban setting. Contraception 2004; 70:121. 